\title{
Absent p53 Immunohistochemical Staining in a Pituitary Carcinoma
}

\author{
Krishna Kumar, Robert J.B. Macaulay, Michael Kelly, Tyler Pirlot
}

\begin{abstract}
Background: Carcinomatous transformation of pituitary adenomas is uncommon, and is generally accompanied by nuclear accumulation of p53 protein. Pituitary carcinoma lacking accumulation of p53 protein is very rare, only two such cases being previously reported. Methods: A patient presented with visual disturbance and cranial nerve palsies and was found to have a suprasellar mass. He underwent both transphenoidal and transfrontal excision of a nonfunctioning pituitary adenoma which recurred several times. The third recurrence was accompanied by multiple dural-based metastases. Despite aggressive surgical management, he continued to develop additional intracranial lesions and died two years after the discovery of metastatic disease. Specimens from 1984, 1995, 1997 and 1998 were available for histological and immunocytochemical analysis. Antibodies recognizing the pituitary hormones (ACTH, PRL, GH, FSH, LH and TSH), as well as cytokeratin, epithelial membrane antigen (EMA), glial fibrillary acidic protein (GFAP) and chromogranin A were applied to investigate the lineage of the neoplasm. Antisera specific for Ki-67 (MIB-1) and p53 protein were also applied to further delineate the biology of the tumour. Results: Although cytokeratin and chromogranin A were detected in neoplastic cells, no expression of pituitary hormones was demonstrable, indicative of a nonfunctioning, null-cell pituitary adenoma. Nuclear pleomorphism and mitotic activity increased with subsequent resections. Abnormal accumulation of p53 protein was not observed, neither in early resections nor in the metastatic deposits. Conclusions: Failure to demonstrate p53 protein accumulation does not ensure a favourable outcome for pituitary adenoma. Accordingly, pituitary carcinoma may occur in the absence of p53 accumulation. The factors which underlie aggressive behaviour of pituitary neoplasms are uncertain but are under investigation.
\end{abstract}

RÉSUMÉ: Absence de la p53 à la coloration immunohistochimique d'un carcinome pituitaire. Introduction: La transformation carcinomateuse d'un adénome pituitaire est rare et elle est généralement accompagnée par une accumulation nucléaire de la protéine p53. Le carcinome pituitaire sans accumulation de protéine p53 est très rare, seulement deux cas ayant été rapportés à date. Méthodes: On a découvert une masse suprasellaire chez un patient ayant consulté pour des troubles visuels accompagnés d'anomalies des nerfs crâniens. Il a subi une excision par voie transphénoïdale et par voie transfrontale d'un adénome pituitaire non fonctionnel qui a récidivé à plusieurs reprises. La troisième récidive s'est accompagnée de métastases durales multiples. Il a continué à développer des lésions intracrâniennes additionnelles malgré un traitement chirurgical agressif. Le patient est décédé deux ans après la découverte des premières métastases. Des spécimens anatomopathologiques de 1984, 1995, 1997 et 1998 étaient disponibles pour analyse histologique et immunocytochimique. Des anticorps reconnaissant les hormones pituitaires (ACTH, PRL, GH, FSH, LH et TSH), ainsi que la cytokératine, l'antigène de la membrane épithéliale (EMA), la protéine gliofibrillaire acide (GFAP) et la chromogranine A ont été appliqués pour déterminer l'origine du cancer. Un antisérum spécifique pour le Ki-67 (MIB-1) et la protéine p53 ont également été appliqués pour mieux définir la biologie de la tumeur. Résultats: Bien qu'on ait détecté de la cytokératine et de la chromogranine A dans les cellules néoplasiques, aucune expression d'hormones pituitaires n'a été observée, ce qui indique qu'il s'agissait d'un adénome pituitaire non fonctionnel à cellules nulles. Le pléomorphisme nucléaire et l'activité mitotique ont augmenté d'une résection à l'autre. Une accumulation anormale de la protéine p53 n'a pas été observée, que ce soit dans les premières résections ou dans le tissu métastatique. Conclusions: Le fait de ne pas observer d'accumulation de la protéine p53 ne garantit pas un bon pronostic chez les cas d'adénomes pituitaires. Il peut s'agir d'un carcinome pituitaire, même s'il n'y a pas d'accumulation de la protéine p53. Les facteurs sous-jacents au comportement agressif des néoplasies pituitaires sont mal connus et demeurent à l'étude.

Can. J. Neurol. Sci. 2001; 28: 174-178

Attempts to assign a histologic grade to pituitary adenomas has proven largely futile, since similar-appearing examples may vary widely in biologic behaviour. Features such as nuclear pleomorphism, mitotic rate, increased cellularity and even necrosis are not reliable indicators of aggressive biology, as determined by growth rate, likelihood of recurrence, propensity for local invasion and capacity to metastasize.$^{5,17}$ Determination of the production of hormones by neoplastic cells (functioning vs nonfunctioning) adds to the understanding of tumour histogenesis but does not contribute to determining prognosis. There are some exceptions to this generalization, such as for the rare acidophil stem cell adenoma, the diagnosis of which implies an increased likelihood of recurrence. ${ }^{18}$

Some authors have espoused increased p53 immuno-

From the Department of Surgery, Section of Neurosurgery, Regina General Hospital, University of Saskatchewan, Regina, Saskatchewan, (KK, MK, TP); and Department of Pathology and Laboratory medicine, Queen Elizabeth II Health Science Centre, Dalhousie University, Halifax, Nova Scotia, (RM) Canada

ReCEIVED MarCh 21, 2000. ACCEPTED IN FinAL FORM JANUARY 18, 2001. Reprint requests to: Krishna Kumar, Suite 121, Medical Office Building, Regina General Hospital, 1440 14th Avenue, Regina, Saskatchewan, Canada, S4P 0W5 

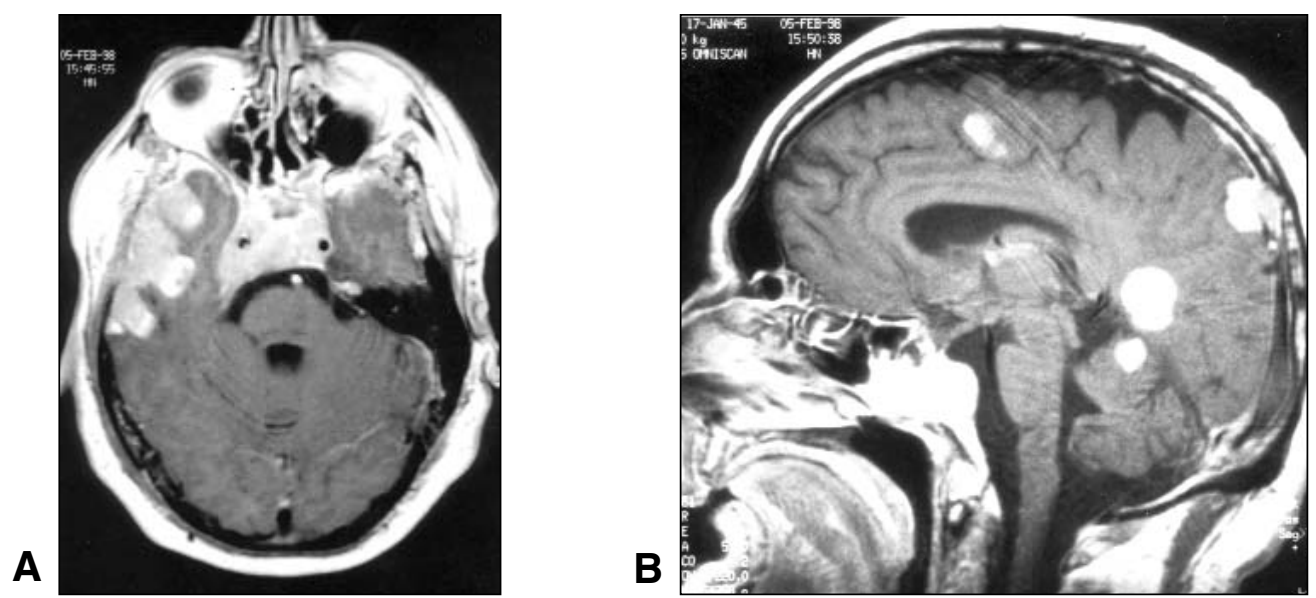

Figure 1: A) Axial magnetic resonance imaging from February 15, 1998, T1 weighted with gadolinium enhancement, showing large temporal dural metastases and invasion of the right cavernous sinus.

B) Sagittal magnetic resonance imaging from February 15, 1998, T1 weighted with gadolinium enhancement, demonstrating the recurrence of the pituitary tumor filling the sphenoid sinus and multiple enhancing dural and paranchymal nodules.

histochemical staining as a reliable biomarker of aggressiveness, invasive potential and probability of malignant transformation. The p53 gene is the most commonly mutated gene in human cancer, and encodes a protein which acts as a tumour suppressor by arresting mitotic activity and/or inducing programmed cell death. Mutation of the p53 gene may lead to detectable p53 protein accumulation in some neoplasms. However, p53 gene mutation is a rare event in pituitary neoplasia and has not been correlated with protein accumulation or aggressive potential. We present a case of nonfunctioning pituitary adenoma which progressed to pituitary carcinoma despite the absence of p53 protein accumulation.

\section{CASE Report}

A 38-year-old Caucasian male initially presented to our institution in 1983 with reduction of visual acuity and diplopia. Endocrinologic findings were absent and pituitary hormone levels were normal. He was found to have a nonsecreting pituitary adenoma which was treated by transsphenoidal excision followed by radiotherapy. He exhibited hypopituitarism after the initial resection which was successfully managed with supplementary hormone replacement.

He did well until 1993, when he again presented with diplopia. Investigations revealed recurrence of his pituitary adenoma. Transphenoidal resection with total removal of the tumour was performed at another institution. However, the benefit of the second surgery was short-lived, as he developed headaches, right third, fourth and sixth nerve weakness and right eye proptosis over the next six months. At this time visual fields were full. Magnetic resonance (MR) imaging showed recurrence of the tumour filling the sphenoid sinus and invading the right cavernous sinus.

In January 1995, he underwent a right frontal craniotomy. Only partial excision was possible because the tumour was very fibrous and firm. In view of the infiltration and partial occlusion of the right cavernous sinus, supplementary radiotherapy was given postoperatively. Follow-up MR imaging in January and November of 1995 showed slight shrinkage of residual tumour.
In January 1997, he had recurrence of headaches. MR imaging with, and without, gadolinium enhancement showed a $3 \mathrm{~cm}$ enhancing mass within the sella and right cavernous sinus, consistent with recurrent pituitary adenoma. Multiple small enhancing dural-based masses were identified over both cerebral hemispheres. The two largest lesions were on the right side above and below the Sylvian fissure.

By July 1997, two of the temporal lesions had increased in size and were causing pressure effects. A right frontal craniotomy was performed and these two lesions were excised. At surgery, these nodules were lightly attached to the undersurface of the dura without invasion of the brain parenchyma. After brief symptomatic improvement, he presented in February 1998 with recurrent headaches and seizures. At this time, his appearance was cushingoid due to dexamthasone he was receiving as a part of his hormonal therapy. MR imaging showed growth of several dural based lesions situated in the right frontal and temporal regions causing pressure effects (Figure 1A). Metastatic lesions were also seen in brain parenchyma (Figure 1B). The large metastases in the right temporal area were excised to give palliative relief. After brief improvement, he deteriorated and succumbed to his illness in December of 1998 . The family did not permit an autopsy.

\section{Pathologic Studies}

Specimens from 1983, 1995, 1997 and 1998 showed similar morphologic features of a neoplasm with a subtle nesting or sinusoidal pattern (Figure 2A). In some trabecular areas, subtle discohesion yielded a pseudopapillary appearance. Expansion and effacement of the normal pituitary reticulin network was seen in all histologic specimens.

Neoplastic cells possessed abundant eosinophilic finely granular cytoplasm, often with indistinct cell borders. Nuclei were oval with inconspicuous nucleoli, although, with progression of the tumour nucleoli, gained moderate prominence (compare Figures 2B and 2C with 2D). The 1983 specimen showed mild nuclear pleomorphism (Figure 2B); the 1995 specimen showed minimally increased pleomorphism (Figure 2C) and the specimens from 1997 (Figure 2D) and 1998 (not 


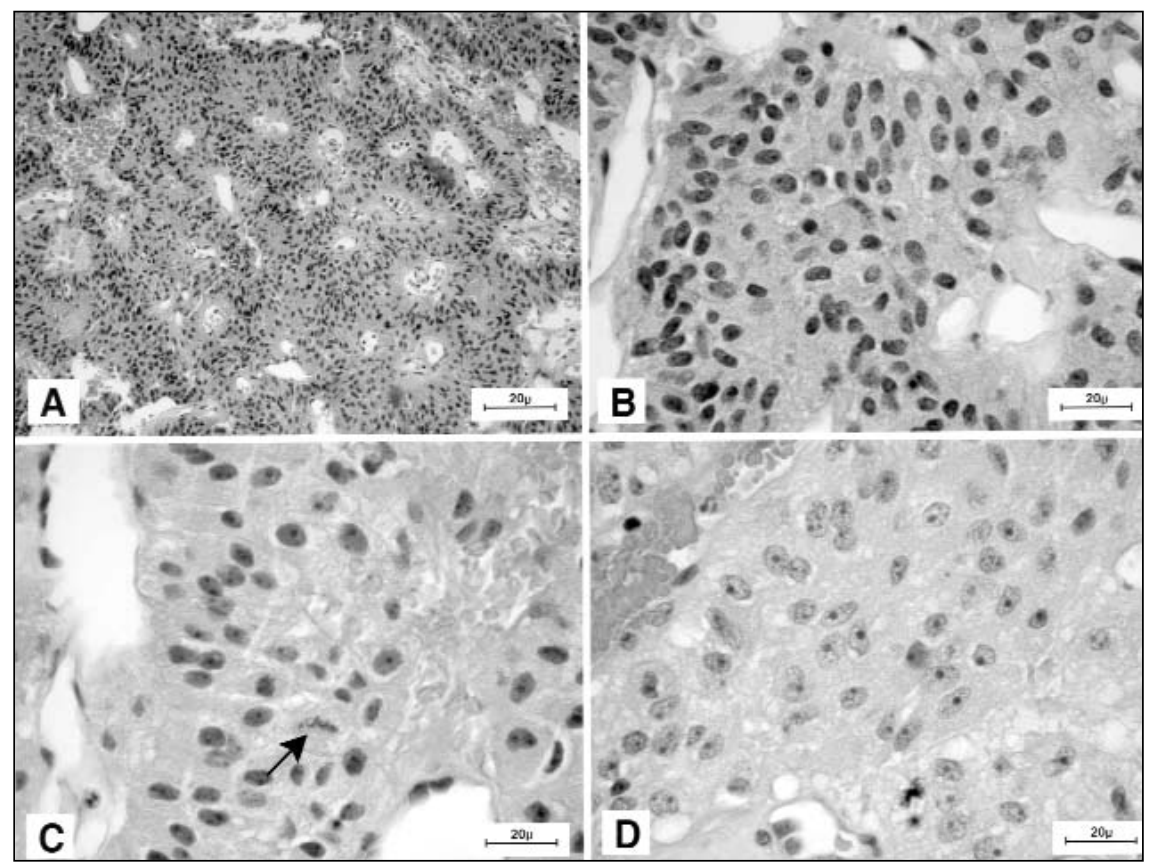

Figure 2: Architecture and cytology.

A) Low power view of 1983 specimen showing moderate cellularity, small dense nuclei and loose perivascular arrangement of cells (haematoxylin and eosin).

B) High power view of 1983 specimen. Note the mild nuclear pleomorphism. Reticulin stain shows expansion of the reticulin network

C) High power view of 1995 specimen, with visible nucleoli and mitosis (arrow).

D) High power view of 1997 specimen. Nucleoli are more prominent than in previous samples and nuclear pleomorphism is increased.

shown) showed moderate nuclear pleomorphism, and slightly increased cellularity.

The mitotic rate increased from scattered (1 per 10 high powered field (HPF)) in 1983 to moderate (3/10 HPF) in 1995 (Figure 2C), with a mild further increase (up to 4 per $10 \mathrm{HPF}$ ) between 1995 and 1997; again the 1998 specimen was similar to 1997.

Immunostaining for a variety of relevant antigens was undertaken using standard techniques and chromogen diaminobenzidine (DAB). The epithelial lineage of the cells is confirmed by strong immunopositivity for cytokeratin (CAM 5.2, Bectin + Dickenson, $1 / 20$ dilution); epithelial membrane antigen (EMA) was negative (not shown). To exclude the possibility of an unusual neuroglial tumour, glial fibrillary acidic protein (GFAP) immunostaining was performed, and was negative (not shown). Patchy chromogranin A positivity was detectable. Immunohistochemical search for expression of the six pituitary hormones (adrenocorticotrophic hormone [ACTH],

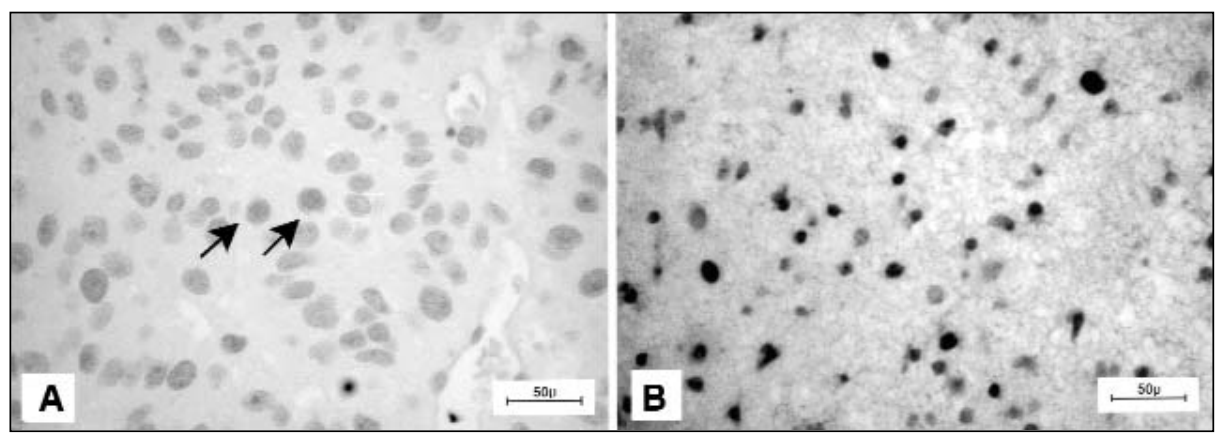

Figure 3: Immunohistochemistry.

A) Immunopositivity for p53 is absent except for rare slightly beige nuclei (arrows) 1997 specimen; (compare with strongly positive control - Figure 3B)

$B$ ) Strong and widespread p53 immunopositivity in the nuclei of high grade astrocytoma for comparison with absent or poor labeling in the pituitary carcinoma illustrated in Figure $3 \mathrm{~A}$. 
prolactin $[\mathrm{PRL}]$, growth hormone $[\mathrm{GH}]$, luteinizing hormone $[\mathrm{LH}]$, follicle stimulating hormone $[\mathrm{FSH}]$ and thyroid stimulating hormone $[\mathrm{TSH}]$ was negative.

Using Ki-67 (MIB-1) antisera, the increase in proliferative rate appreciated on morphologic grounds was confirmed; interestingly, the most obvious increase in frequency of proliferating cells was between the $1983(<1 \%)$ and 1995 (about $2 \%$ ) specimens, with only mildly increasing frequency in 1997 (about 2\%) and 1998 specimen (about 2\%). Labeling indices were obtained by assessing 100 cells in four high powered fields exhibiting the most numerous positive cells.

Immunohistochemical detection of $\mathrm{p} 53$ protein was attempted after standard microwave antigen retrieval. The original resection, the 1995 resection, the 1997 resection of metastases and the 1998 resection of secondary tumour failed to show any significant accumulation of $\mathrm{p} 53$ protein, with only rare weakly immunopositive nuclei in the 1997 specimen (Figure 3A), within the physiologic range. Note that strongly positive (astrocytoma grade IV) (Figure 3B) and negative controls were used for all assays.

The morphologic and immunohistochemical profile was diagnostic of a nonfunctioning null-cell pituitary adenoma. Material was not available for electron microscopy. The clinical, neuroimaging and pathologic findings were diagnostic of pituitary carcinoma arising from a nonfunctioning pituitary adenoma.

\section{DiscuSsION}

\section{Role of surgery in dissemination of this neoplasm}

At the time of craniotomy in January 1995, there were no arachnoid nodules. Although the tumor had a suprasellar bulge there was no invasion of suprasellar space.

In this case, the possible mechanism of the spread is secondary to the seeding of the tumour cells when the patient underwent craniotomy for removal of the recurrent tumour. This was the only time when the tumour cells would have had access to the cerebral spinal fluid pathways.

\section{Pathogenesis of pituitary adenomas and carcinomas}

The molecular mechanisms underlying the pathogenesis of pituitary adenomas are largely unknown. Although a frequent manifestation of Multiple Endocrine Neoplasia Type I (MEN$1),{ }^{1}$ the gene to which this familial tumour disorder has been ascribed is not implicated in sporadic adenomas. ${ }^{2}$ Comparative genomic hybridization has implicated previously unsuspected chromosomal regions in the pathogenesis of pituitary adenomas ${ }^{2}$ notably, the p53 locus was not amongst those found to be involved. A recently described transcription factor which may participate in pituitary neoplasia is Zac1, which induces cell cycle arrest independently of $\mathrm{p} 53 .^{3}$

Metastatic potential depends on the ability of neoplastic cells to survive in the subarachnoid space or bloodstream, burrow into the recipient tissue, and survive in an unfamiliar environment. Some of the molecular mechanisms allowing this to occur in other epithelial neoplasms, especially squamous cell carcinoma, have been established but application of these data has been limited in pituitary neoplasms. ${ }^{4}$ The lack of histologic anaplasia in most pituitary carcinomas and the adenomas from which they arise, raises the possibility that relatively few genetic 'hits' are required but perhaps in selected, rarely involved loci.

In our patient, progression of his nonfunctioning pituitary neoplasm from adenoma to disseminated carcinoma was accompanied by only subtle progression of histologic atypia. No histologic criteria currently exist which reliably distinguish adenoma from carcinoma, ${ }^{5}$ nor indolent (or incidental) adenomas from aggressive and invasive (but not metastatic) adenomas. The clinical diagnosis of pituitary carcinoma continues to rely on demonstration of intracranial, intraspinal or systemic metastasis. The identification of immunohistochemical or molecular markers of increased aggressiveness would be valuable in predicting clinical outcome; determination of Ki67 labeling index $^{6}$ or $n m 23$ gene expression ${ }^{4}$ in invasive adenomas are currently being studied.

\section{p53 Protein in pituitary neoplasms}

A possible role for p53 in the pathogenesis of aggressive pituitary neoplasms emerged from data showing accumulation of p53 protein in some invasive adenomas. ${ }^{7}$ Subsequently, a high proportion of pituitary carcinomas was found to exhibit p53 protein accumulation. Indeed, it has been hypothesized that p53 immunopositivity in a pituitary adenoma may be an independent predictor of recurrence and eventual metastatic spread; p53 immunonegative tumours are more likely to remain indolent. ${ }^{8}$

Mutations of the p53 tumour suppressor gene have been associated with a wide variety of sporadic neoplasms. ${ }^{9}$ p53 protein is highly expressed, localizes to cell nuclei and interacts with both DNA and other nuclear proteins to alter the transcription of a variety of cellular genes. ${ }^{10} \mathrm{p} 53$ protein plays a pivotal role in DNA repair, forcing arrest of cell cycling when replication errors are detected, ${ }^{11,12}$ through upregulation of the cyclin-dependent kinase inhibitor p21WAF1. As well as inducing cell cycle arrest, p53 protein may induce programmed cell death through upregulation of the pro-apoptotic protein bax. ${ }^{13,14}$

The inability of mutant p53 protein to arrest cell cycling and induce apoptosis in cells with DNA damage is suspected to allow the propagation of further genomic alterations. The accumulation of such additional mutations likely accounts for progressive anaplastic transformation over time. Thus, it would not be surprising if p53 aberrations were predictive of future malignant behaviour.

Immunohistochemistry for the p53 protein is more convenient than molecular techniques, because mutant p53 protein has an increased half-life and thus accumulates to detectable levels. Despite variable accumulation of p53 protein, however, mutation of the p53 gene is very rare in pituitary neoplasia. ${ }^{15}$ Physiological upregulation of p53 may also result in accumulation of detectable protein levels, as a response to ionizing radiation or other DNA damaging agents. ${ }^{11,12}$ Thus, the poor correlation between immunodetection and mutation of p53 in pituitary adenomas may reflect alternative mechanisms by which p53 influences tumour cell growth. ${ }^{15}$ Our observation of rare cells accumulating minimal p53 in the third resection specimen (Figure 3A), after metastatic spread had occurred, is interpreted to indicate physiologic upregulation in isolated cells. Because p53 was completely absent in the two previous specimens, intracranial dissemination was unexpected.

The vast majority of aggressive or frankly malignant pituitary neoplasms exhibit significant immunopositivity for $\mathrm{p} 53$ protein ;- $^{5-}$ 
8,16 absence of p53 immunopositivity has thus been associated with a reduced likelihood of aggressive behaviour. Besides our report, only two other published cases of pituitary carcinoma lacked p53 protein immunopositivity. ${ }^{5}$ Nevertheless, the existence of these cases cautions against favourable prognostication in pituitary adenomas lacking $\mathrm{p} 53$ protein accumulation.

\section{REFERENCES}

1. Hosoi E, Yokogoshi Y, Hosoi E, et al. A pituitary specific point mutation of codon 201 of the Gs alpha gene in a pituitary adenoma of a patient with multiple endocrine neoplasia (MEN) type 1. Endocrinol Jpn 1992; 39: 319-324.

2. Daniely M, Aviram A, Adams EF, et al. Comparative genomic hybridization analysis of nonfunctioning pituitary tumors. J Clin Endocrinol Metab 1998; 83: 1801-1805.

3. Spengler D, Villalba M, Hoffmann A, et al. Regulation of apoptosis and cell cycle arrest by Zac1, a novel zinc finger protein expressed in the pituitary gland and the brain. EMBO J 1997; 16 : 2814-2825.

4. Takino H, Herman V, Weiss M, Melmed S. Purine-binding factor (nm23) gene expression in pituitary tumors: marker of adenoma invasiveness. J Clin Endocrinol Metab 1995; 80: 1733-1738.

5. Pernicone PJ, Scheithauer BW, Sebo TJ, et al. Pituitary carcinoma: a clinicopathologic study of 15 cases. Cancer 1997; 79: 804-812.

6. Thapar K, Kovacs K, Scheithauer BW, et al. Proliferative activity and invasiveness among pituitary adenomas and carcinomas: an analysis using the MIB-1 antibody. Neurosurgery 1996; 38: 99106, discussion 106-107.

7. Buckley N, Bates AS, Broome JC, et al. p53 Protein accumulates in Cushings adenomas and invasive nonfunctional adenomas. J Clin Endocrinol Metab 1995; 80: 692-696.
8. Thapar K, Scheithauer BW, Kovacs K, et al. p53 Expression in pituitary adenomas and carcinomas: correlation with invasiveness and tumour growth fractions. Neurosurgery 1996; 38: 763-770; discussion 770-771.

9. Marks JR, Davidoff AM, Kerns BJ, et al. Overexpression and mutation of p53 in epithelial ovarian cancer. Cancer Res 1991; 51: 2979-2984.

10. Levine AJ, Momand J, Finlay CA. The p53 tumour suppressor gene. Nature 1991; 351: 453-456.

11. Cohen JJ, Duke RC, Fadok VA, Sellins KS. Apoptosis and programmed cell death in immunity. Annu Rev Immunol 1992; 10: 267-293.

12. Kuerbitz SJ, Plunkett BS, Walsh WV, Kastan MB. Wild-type p53 is a cell cycle checkpoint determinant following irradiation. Proc Natl Acad Sci USA 1992; 89: 7491- 7495.

13. Yonish RE, Resnitzky D, Lotem J, et al. Wild-type p53 induces apoptosis of myeloid leukaemic cells that is inhibited by interleukin-6. Nature 1991; 352: 345-347.

14. Miyashita T, Reed JC. Tumor suppressor p53 is a direct transcriptional activator of the human bax gene. Cell 1995; 80: 293-299.

15. Levy A, Hall L, Yeudall WA, Lightman SL. p53 gene mutations in pituitary adenomas: rare events. Clin Endocrinol (Oxf) 1994; 41: 809-814.

16. Nagasaka $T$, Nakashima $N$, Furui A, et al. Sarcomatous transformation of pituitary adenoma after bromocriptine therapy. Hum Pathol 1998; 29: 190-193.

17. Scheithauer BW, Kovacs KT, Lawser ER, Randall RV. Pathology of invasive pituitary tumors with special reference to functional classification. J Neurosurg 1986; 65: 733-744.

18. Asa SL. Tumors of the pituitary gland. In: Rosai J, ed. Atlas of Tumor Pathology, Fascicle XXII. Series 3. Washington DC: Armed Forces Institute of Pathology. 1998; 76-86. 